\title{
Effects of using an integrated team-based and problem- based learning approach for developing lifelong learning characteristics of first year medical students
}

\author{
Paitoon Chuangchum, Thirdsak Pholchan, Tawesak Nopkesorn, Supasit Pannarunothai
}

\begin{abstract}
Objectives: To examine the effects of using an integrated team-based learning (TBL) with problembased learning (PBL) approach for developing lifelong learning in the professional development (PD1) course for first year medical students.

Method: Mixed methods study examined the effects on learning of using an integrated TBL with PBL approach and also aimed at expanding the understanding of elements and factors influencing the development of lifelong learning characteristics of 124 first year medical students. A quasiexperimental, pre-post design was used, involving the collection of quantitative data, followed by a qualitative phase using focus group discussions.
\end{abstract}

Results: Findings demonstrated that an integrated TBL with PBL approach is an effective teaching strategy, which delivered higher lifelong learning skill levels. The significant elements of the effective teaching strategy in the integrated TBL with PBL approach were the core elements of infrastructure (i.e., active processes of students, lecturers, tutor-monitored, peers, instructional techniques, student support services, content and problems acting as a stimulus for learning) and enabler factors (i.e., collaboration, trust, teamwork, time management, motivation and care for learning).

Conclusion: The integrated TBL with PBL approach was an effective teaching strategy for developing lifelong learning characteristics of first year medical students at Naresuan University.

Key words: Lifelong learning, team-based learning, problem-based learning

\section{Introduction}

Arising from globalization and the knowledgebased economy, lifelong learning has become a critical factor in Thailand's educational reform. Since 1999, the National Education Act has required educational institutions to emphasize student-centered learning and to develop in students lifelong learner characteristics (Satayasai, 2004: 3-4). The goals of this effort include higher student achievement, higher academic standards and curricula, including changing their teaching improved lifelong learning skills. Therefore, educational institutions need to adjust their strategies, from being based on the traditional

Department of Community Family and Occupational Medicine, Faculty of Medicine, Naresuan University, Phitsanulok 65000, Thailand, lecture format, which is a form of passive learning to active learning methods. Specifically, active learning methods, such as team-based learning (TBL) and problembased learning (PBL), have been widely accepted as effective teaching methods and are increasingly popular in the modern curricula of medical schools for developing lifelong learning (Holen, 2000; Clark et al., 2008; Michaelsen et al., 2008).

There is evidence that PBL is an instructional method which focuses on students learning through facilitated problem solving (Tan, 2003). It also fosters self-directed learning and develops students' lifelong learning characteristics (Holen, 2000). The PBL approach has many advantages, such as: 1) it develops the personal competence in problem solving, critical reasoning (Kelly et al., 2002), communication and social skills (Hmelo-Silver, 2004); 2) it increases the learner's effective to work in small groups; 3 ) it fosters self-directed 
and lifelong learning (Holen,2000; Michaelsen, et al.,2008); 4) PBL students become effective collaborators; and 5) it increases intrinsically motivated learning (Barrows \& Kelson,1995). However, the main limitation of the PBL approach is that it is difficult to manage and implement in terms of time and resources (Michaelsen \& Richards, 2005; Michaelsen et al., 2008). PBL takes more time for teaching, it requires clear policies, strong support from top managers, and instructors who have the skills to facilitate PBL (Haden \& Davis, 1999; Sefton, 1997; Kelly et al., 2002; Satayasai, 2004).

Another kind of active learning, TBL is a small group-based instructional strategy that has been used to limit the number of faculty facilitators (Thomson et al., 2007). The principles of TBL provide a universal framework that enhances effective teaching strategy and is suitable for large groups of students, with a student to faculty ratio of as high as 200:1 (Michaelsen et al., 2008).

Many practitioners of TBL have argued that the benefits of TBL include increased student engagement and enhanced student competencies in lifelong learning characteristics, such as communication, interpersonal, teamwork, applying knowledge to real-world problems, critical thinking, attitude about learning, teamwork, and increased student knowledge performance (Moffett \& Hill, 1997; Hunt et al., 2003; Haidet et al., 2004; Michaelsen et al., 2008; Clark et al., 2008).

Both the TBL and PBL approaches have been implemented successfully in western university medical schools, such as at Harvard University in the US and the University of Sydney, Australia (Sefton, 1997). Most evaluation studies implemented only the TBL or the PBL method. There is a lack of studies to apply and integrate the advantages of TBL and PBL methods into teaching strategies for developing lifelong learner competence. Therefore, the most effective alternative teaching strategy for improving pedagogy and developing lifelong learning characteristics in medical curricula is to implement a medical education program using an integrated TBL with PBL approach. The main advantage of this approach is that it adopts an integrated principle of active learning methods and selfdirected learning through the teaching and learning processes which may prepare and enhance students to possess lifelong learning skills (i.e. problem-solving, self-management, comprehension and summarizing abilities, management of information, information handling, oral presentation skills, learning to learn, practical skills, critical thinking, creativity, collaboration, teamwork, flexibility and adaptation, leadership, communication, reflection, self- awareness, team learning, teamwork and the ability to construct figures with symbols in appropriate presentations (Longworth \& Davies, 1996, pp. 50-62; Cornford, 2002; Li, et al., 2006).

The Faculty of Medicine, Naresuan University is a medical school that has a crucial role in preparing medical gaduates for continuous professional development along the continuum of lifelong learning. In particular, its vision is to provide a quality curriculum and instructional improvements for developing self-directed and lifelong learning. In the past, the faculty had operated a "learning how to learn" program through PBL for three days at the beginning of the second year for preparing medical students in their clinical years. One lesson learned from this program is that the faculties found that it came too late and they had only a short time to help the medical students to change their orientation from lecture-based learning at high schools to a learning process in the Faculty of Medicine. The curriculum needs to improve the teaching and instructional methods by integrating the principles of active learning methods and selfdirected learning through the teaching and learning processes at the beginning of the first year for medical students (Self-Assessment Report in Pilot Accreditation of FMNUH, 2009:13-14).

In 2009, the Faculty of Medicine implemented an integrated TBL and PBL approach in the Professional Development 1 (PD1) course in the first semester of the first year medical student program. The ultimate outcome of this course is the readiness in pre-medical years of medical students to develop the characteristics of lifelong learners. This article aims to present the effects of using an integrated TBL with PBL approach for developing lifelong learning in the PD1 course for the first year medical students, compared with the prior experiences of students.

The main research question of this study was whether the change in the lifelong learning characteristics occurred after exposure to the integrated TBL with PBL approach in the PD1 course. 


\section{Methodology}

This study examined the effects of using an integrated TBL with PBL approach for developing lifelong learning in the PD1 course for the first year medical students, compared with their prior experience in traditional teaching methods at high school. It involved collecting qualitative data after a quantitative phase, in order to explore on results from the quantitative method in more depth. In the first phase, a quantitative study, a quasi-experimental, pre-post design was used to compare the differences in the first year medical students' lifelong learning characteristics when an integrated TBL and PBL approach was used in the PD1 course, versus the traditional, teachercentered pedagogy used at high schools. Questionnaires were administered to 124 first year medical students at Naresuan University. The second, qualitative phase was conducted with a follow-up of 8 first year medical students whose lifelong learning scores increased more than two points from using open-ended questions to assess their in-depth perceptions about what factors influenced the change in their lifelong learning skills. The reason for the exploratory follow-up was to help explain the initial quantitative results

The instruments included the 20-item Likertscale questionnaires constructed to measure students' lifelong learning characteristics, open-ended opinion questions and a focus group protocol. Two independent experts evaluated the instruments' content validity. Following the above process, the researcher conducted a pilot test with 30 first year dentistry students at Naresuan University to test the reliability of the instrument before it was used in this study. A Cronbach alpha coefficient of 0.93 demonstrated the questionnaire's high reliability.

In this study, the researcher collected data on the lifelong learning instrument prior to and after implementing the integrated TBL with PBL approach in the PD1 course with 124 medical students at Naresuan University.

The reliability of the instrument by Cronbach Alpha coefficient was as high as 0.89 and 0.85 for pre- and posttest respectively. Data were analyzed using descriptive statistics of means and standard deviations, inferential statistics of t-tests for dependent groups and content analysis.

\section{Results}

Different characteristics of lifelong learning The study found that most participants aged from 17-19 years old, with 5\% aged 20 years and above. All the participants have had experience in a traditional lecture format for a period of at least twelve years. The most preferred teaching approach by $42 \%$ of the students was an integrated TBL with PBL approach used in the PD1 course, while 35\% favored the lecture format, with $8 \%, 7 \%$ and $6 \%$ chose the PBL,TBL and self directedlearning $(\mathrm{SDL})$ respectively.

The target group's lifelong learning skills improved, after the integrated TBL with PBL approach in the PD1 course was implemented. There was a significant improvement from pretest to posttest for all the 20 lifelong learning items measured, as well as a highly significant level of total improvement. The lifelong learning scores increased from an average of 58.87 to $76.82(\mathrm{t}=14.27, \mathrm{p}<0.001)$, as shown in Table1. Similar patterns were found for each part of the skills, leading to the conclusion that the integrated TBL with PBL, as used in the PD1 course, was an effective method for developing lifelong learning skills for first year medical students who participated for one semester in the integrated TBL with PBL approach in the PD1 course at Naresuan University.

\section{Changes in attitude after participating in an integrated TBL with PBL course}

The first year medical students' opinions participating in an integrated TBL with $\mathrm{PBL}$ approach in PD1 course revealed several important findings. Participants believed that an integrated TBL with PBL approach, as used in the PD1 course, had changed their lifelong learning characteristics, more so than from the traditional pedagogy used in high school. They had also reflected on their experiences in different themes between high school and an integrated TBL with PBL teaching approach, such as more emphasis on collaborative learning, personal mastery, building relationships and trust, an active process of students, teamwork, time management, prepare reading and spend time studying the assigned materials individually before class. 
Tablel 1: Mean and standard deviations of the scores of lifelong learning skills before and after implementing an integrated TBL with PBL approach.

\begin{tabular}{|c|c|c|c|c|c|c|c|}
\hline \multirow{2}{*}{\multicolumn{2}{|c|}{ Lifelong learning characteristics }} & \multicolumn{4}{|c|}{$\begin{array}{l}\text { Scores of the lifelong learning skills before and } \\
\text { after an integrated TBL with PBL in the PD1 course }\end{array}$} & \multirow{2}{*}{ t-test } & \multirow{2}{*}{ P-value } \\
\hline & & $\begin{array}{l}\text { Pre-test } \\
\text { Mean }\end{array}$ & $\begin{array}{l}\text { Pre-test } \\
\text { SD }\end{array}$ & $\begin{array}{l}\text { Post-test } \\
\text { Mean }\end{array}$ & $\begin{array}{l}\text { Post-test } \\
\text { S.D }\end{array}$ & & \\
\hline 1 & Comprehend \& summarize & 3.089 & 0.625 & 3.734 & 0.572 & 11.008 & $<.001$ \\
\hline 2 & Self-management & 2.919 & 0.632 & 3.952 & 0.508 & 16.476 & $<.001$ \\
\hline 3 & Information handling & 3.153 & 0.766 & 3.919 & 0.593 & 11.456 & $<.001$ \\
\hline 4 & Management information & 2.790 & 0.678 & 3.823 & 0.625 & 16.207 & $<.001$ \\
\hline 5 & Self awareness & 3.323 & 0.802 & 3.984 & 0.611 & 11.137 & $<.001$ \\
\hline 6 & Collaborator & 2.290 & 0.506 & 3.790 & 0.465 & 25.940 & $<.001$ \\
\hline 7 & Practical skills & 2.855 & 0.646 & 3.855 & 0.580 & 16.503 & $<.001$ \\
\hline 8 & Management & 2.871 & 0.674 & 3.710 & 0.635 & 11.978 & $<.001$ \\
\hline 9 & Team learning & 3.016 & 0.732 & 4.081 & 0.670 & 14.056 & $<.001$ \\
\hline 10 & Teamwork & 2.919 & 0.632 & 3.839 & 0.603 & 15.013 & $<.001$ \\
\hline 11 & Problem-solving & 2.782 & 0.771 & 3.815 & 0.616 & 15.951 & $<.001$ \\
\hline 12 & Critical thinking & 2.718 & 0.657 & 3.637 & 0.589 & 18.136 & $<.001$ \\
\hline 13 & Flexibility \& adaptation & 3.129 & 0.662 & 3.976 & 0.563 & 14.776 & $<.001$ \\
\hline 14 & Creative thinking & 2.798 & 0.675 & 3.589 & 0.612 & 13.728 & $<.001$ \\
\hline 15 & Leadership & 2.944 & 0.747 & 3.734 & 0.664 & 10.743 & $<.001$ \\
\hline 16 & Create the figure \& symbols & 2.984 & 0.743 & 3.661 & 0.720 & 9.785 & $<.001$ \\
\hline 17 & Oral presentation & 2.935 & 0.707 & 3.726 & 0.642 & 11.459 & $<.001$ \\
\hline 18 & Communication & 3.266 & 0.700 & 4.024 & 0.643 & 11.460 & $<.001$ \\
\hline 19 & Self-learning reflection & 3.056 & 0.736 & 3.992 & 0.577 & 14.064 & $<.001$ \\
\hline 20 & Learning to learn & 3.032 & 0.662 & 3.976 & 0.618 & 15.488 & $<.001$ \\
\hline & Total & 58.87 & 13.753 & 76.82 & 12.106 & 14.27 & $<.001$ \\
\hline
\end{tabular}

Additionally, the results of the exploratory follow up with 8 participants' opinions whose scores increased more than 2 points revealed two important findings. The target group believed that the following two factors were important to influence the big increase in their lifelong learning scores to achieve successful lifelong learning characteristics and develop themselves: 1) core elements of teaching infrastructure, i.e., active processing of students, tutor's roles as a mentor and monitor, peers' and group's roles, instructional techniques, student support services, content of the PD1 course and problems acting as a stimulus for learning; and 2) enabler factors (i.e., collaboration, trust, teamwork, time management, motivation and care for learning).

\section{Discussion}

The key findings of this study revealed that an integrated TBL with PBL approach, as used in the PD1 course, encouraged the first year medical students to move towards the development of lifelong learning skills with higher score changes in the collaborative, critical thinking, practical and apply knowledge for solving a problem, self-management, management information, problem solving, learning to learn, and teamwork skills. Because this approach was designed to emphasize the strong points of TBL and PBL methods, it enhanced students' competencies to be lifelong learners, increasing such skills as communication, teamwork, applying knowledge to real problems, critical thinking, attitudes about learning, teamwork and problem solving, critical reasoning, and led to an increase learners effectively working in small groups, fostering self-directed and lifelong learning (Holen, 2000; Michaelsen et al., 2008; Hunt et al., 2003; Haidet et al., 2004; Clark et al., 2008; Barrows \& Kelson, 1995; Kelly et al., 2002). Specifically, this approach facilitated an effective collaboration for sharing 
and creating mutual learning within student groups, including between tutors and students. This change occurred through the process of taking the problems as a stimulus for learning, as well as based on the strong points of the TBL and PBL methods, emphasizing cooperative and collaborative learning in the PD1course. Moreover, this approach was designed as an underlying force in the Thai cultural education, that involved, not only the use of the peer group relationship system, but also with special care for learning from tutors as mentors for each group's students. Both the peer group and the tutors, as a form of mentor-monitor relationship, are quite important, as well as a belief in working together closely in Thai society. Many factors, such as showing kindness, thinking of minds, concern and caring for each group's students, are included in this context. All these factors underlie the basic relationships of Thai people. Particularly important is the strong tutors and students relationship system that includes loving, concern, sympathizing, thinking of each other's perspectives, and caring for learning (Mulder, 2000; Komin, 1990), which assisted in developing lifelong learning skills. Additionally, values are expressed through the culture, where caring for learning between tutors and students, caring for peers within the group are the strong points that the researcher used to design an integrated TBL with PBL approach in the PD1 course.

Although the results of an integrated TBL with PBL approach was effective in increasing the skills of lifelong learning in the first year medical students, it was surprising that only $42 \%$ of the students preferred and were satisfied with this approach. Almost as many students (i.e., 35\%) prefered a traditional lecture format, whereby a lecturer transmitted the content in a one-way interaction to learners during the class period (Kelly et al., 2002). These may be several explanations for this result. All of the first year medical students reported that they have had experience in a traditional lecture format with a teachercentered classroom learning culture for a period of at least twelve years. As a result, they were more familiar with the lecture format than an integrated TBL with PBL approach. Moreover, they reflected that the advantages of an integrated TBL with PBL approach were different from the traditional lecture format at high school, because the former teaching method enhanced collaborative learning, personal mastery, building relationships and trust, active processing of information by students, time management and teamwork.
Nevertheless, it seems that the extra effort preparing by reading in advance of class and spending time studying the assigned materials individually before class, taking a readiness test on the materials they have read (Michaelsen et al., 2008), including a practical PBL cases study, may have resulted in some students finding this approach difficult and uncomfortable, especially when they faced with this approach for the first time in their learning experience.

During the implementation period of the PD1 course, seven critical elements were needed within the teaching infrastructure. These seven critical elements were: an active processing of students, the tutor's role as a mentor and facilitator, peers' and group's roles, instructional techniques, student support services, content of the PD1 course and problems acting as a stimulus for learning. Development of lifelong learning characteristics was dependent on all seven elements functioning efficiently. These were to be used as a companion with an integrated TBL and PBL approach. The results arising from an integrated TBL and PBL approach were a combination of the advantages of both the active learning strategies and the ability to develop lifelong learning involving the increases in the 20 skills of the first year medical students' potential for preparing them for the clinical years of their medical training and changing pre-clinical medical students' learning approach in the Faculty of Medicine at Naresuan University.

A limitation of the pre-experimental research design is that there was no control group with which to compare the scores of the first year medical students who experienced the TBL with PBL teaching-learning approach. The changes in both lifelong learning skills and student attitudes to this approach were so large as to support the belief that it was the teaching-learning intervention that made the difference in student cognitive and affective outcomes.

\section{Conclusion}

This study examined the effects of using an integrated TBL with $\mathrm{PBL}$ approach for developing lifelong learning in a professional development course for first year medical students, compared with the prior experience of students. The results demonstrated that an integrated TBL with PBL approach, as used in the PD1 course, is a teaching strategy that encouraged the first year medical students to 
move towards the development of lifelong learning skills. This approach also changed students in their use of collaborative learning, personal mastery, motivation, building relationships and trust, an active process of students, and teamwork, all skills that are appropriate for medical school in the Naresuan University context. The research has produced and extended a number of advantages for both the TBL and the PBL method that were found to be statistically and practically significant, by showing the importance of collaboration, trust between peers within a group, the tutor's role as mentor-monitor, instructional techniques, content of the PD1 course, problems acting as a stimulus for learning and the faculty's role in developing student support services, which were based on a teaching infrastructure and enabler factors in the Medical Faculty.

In the follow up of knowledge to be used in a specific medical course, future research should explore the factors related to learning styles and self-directed learning of the first year medical students who were more satisfied with a traditional lecture format they had experienced as passive learners in high school, compared with the learning styles and self-directed learning of the first year medical students who were more satisfied with an integrated TBL with PBL approach. Such findings may help the Faculty to understand the infrastructure factors and elements of teaching instruction that influence students with different learning styles. It also helps tutors to create the appropriate instructional design and to experiment with cooperative classrooms for both tutors and students.

\section{References}

Barrow, H. \& Keelson, A.C. (1995) Problem-based Learning in Secondary Education and the ProblemBased Learning Institute (Monograph 1), Springfield, IL: Problem Based Learning Institute.

Candy, P.C. (2000) Reaffirming a proud tradition: University and lifelong learning. Active Learning in Higher Education, 1(2), pp. 101-125, [online], available at: http:// online.sagepub.com/cgi/ [accessed October 10, 2009].

Clark, M.C., Nguyen, H.T., Bray, C. \& Levine, R. E. (2007) Team-based learning in an undergraduate nursing course, Journal of Nursing Education, 47(3), pp.111-117. [online] available at: http://web.ebs cohost. com/ ehost/ [accessed July 10, 2009].
Cornford, I.R. (2002) Learning-to - learn strategies as a basis for effective lifelong learning, International Journal of Lifelong Learning Education, 21, pp. 357-368, [online], available at: http://online.Sagepub .com. [accessed July 10, 2009].

Haidet, P., Richards, B., Morgan, R.O., Wristers, K., \& Moran, B.J. (2004) A controlled trial of active versus passive learning strategies in a large group setting. Advances in Health Sciences Education, 9(1), pp.15-27. [online], available at: http://web.ebscohost.com. [accessed July 10, 2009]

Harden, R.M.\& Davis, M.H.(1999) Problem-based Learning: A practical guide, Medical Teacher, 15, pp.130-140. [online], available at: http://web. ebscohost.com [accessed July 10, 2009].

Hmelo-Silver, C.E. (2004) Problem-Based Learning: What and how do students learn, Educational Psychology Review, 16(3). [online], available at: http://web. ebscohost.com/ehost/ [accessed August 10, 2009].

Holen, A. (2000). The PBL group: Self reflections and feedback for improved learning and growth, Medical Teacher, 22, 485-488. Available from: http://web.ebscohost.com [Retrieved July 10, 2009].

Hunt, D.P., Haidet, P. Coverdale, J.H., \& Richards, B. (2003) The effect of using team learning in an evidence-based medicine course for medical students. Teaching \& Learning in Medicine, 15(2), 131-9. [online], available at: http://web. ebscohost.com. [accessed July 10, 2009].

Kelly, P. , Haidet, A., Schneider, P., Searle, V., Seidel, N., Charles, L. \& Richards, B. F. (2005) Teaching \& Learning in Medicine, 17(2), pp. 112118. [online], available at: http://web. ebscohost.com [accessed July 10, 2009].

Komin, S. (1990) The Psychology of the Thai People: Values and behavioral patterns. Bangkok: National Institute of Development Administration.

Li, S.C., Kong, S.C., Lee, F.L, \& Henri, J. (2006) Capacity Building for Lifelong Learning: A study of practitioners' perceptions on information literacy framework, Informatics in Education, 5(2), pp. 219232. [online], available at: http://www.fed.cuhk.edu.hk/fllee/Papers/ JournPa/INFE088. [accessed July 10, 2009].

Longworth, N. \& Davies,W.K. (1996) Lifelong Learning. London: Kogan Page.

Michaelsen, L.K., Parmelee, D.X. , McMahon, K. K. \& Levine, R. E., (2008) Team-Based Learning for Health Professions Education, Stylus, VA: Stylus Publishing.

Michaelsen, L.K., Parmelee, D.X. \& Sweet, M. (2008) Team-Based Learning: Small-Group Learning Next Big Step. Number 116, San Francisco: Stylus. 
Wiley.Moffett, B.S. \& Hills, K.B. (1997) The transition to active learning: A lived experience. Nurse Education, 22(4), pp. 44-47. [online] available at: http://www. nursingcenter.com/ library/JournalArticle.asp?Article_ID=102394. [accessed July 10, 2009]

Mulder, N. (2000) Inside Thai Society: Religion, everyday life and change, Chiang Mai: Silkworm Books.

National Education Act B. E. 2542 (1999) Bangkok: Office of National Education Commission.

Learning Reform: Learner-Centered (2000) Bangkok: Office of National Education Commission.

Satayasai, W. (2004) Problem-Based Learning as a Student-Centered Learning, Bangkok: Booknet.
Sefton, A.J. (1997) From a traditional to a problembased curriculum: Estimating staff time and resources. Education for Health: Change in Learning \& Practice, 10, 165-178. [online], available at: http://web. ebscohost.com. [accessed July 10, 2009].

Tan, O.S. (2003) Problem-based Learning Innovation: Using problems to power learning in the twenty-first century, Singapore: Pearson.

Thompson, B. M., Schneider, V. F., Haidet, P., Levine R. E., McMahon, K. K., Perkowski, L.C. \& Richards, B.F. (2007) Team-based learning at ten medical schools:Two years later, Medical Education, 41, pp. 250-257. available at: http://web.ebscohost.com [accessed July 10, 2009].

WFME Standards for Basic Medical Education (2009) Self Assessment Report Pilot Accreditation of Faculty of Medicine of the Naresuan University and the Affiliated Hospitals. 